\title{
Estática e dinâmica do capitalismo tardio na teoria crítica
}

Caio Vasconcellos* e Vladimir Puzone**

Introdução

Ao longo de suas diferentes fases, a teoria crítica se notabilizou pelo esforço de acompanhar as transformações históricas das sociedades burguesas, atualizando os seus diagnósticos de época. Nos anos de 1930, as problematizações conceituais dos frankfurtianos foram marcadas pela necessidade de entender como o capitalismo passava por mudanças que não poderiam mais ser explicadas recorrendo apenas aos textos clássicos do marxismo. Alguns traços do processo de acumulação do capital ganhavam peso cada vez maior na continuidade da valorização do valor, tais como: a concentração, a centralização e a participação fundamental do estado na regulação da produção e da circulação de capital. Ao lado da derrota dos movimentos socialistas e da vitória do nazifascismo na Europa, o exame de tais aspectos culminaria no célebre debate polarizado entre as figuras de Friedrich Pollock e de Franz Neumann.

Todavia, na elaboração de seus diagnósticos de época, os frankfurtianos também não se furtaram em apontar continuidades que perpassavam diversos momentos históricos das sociedades modernas. Seja em sua fase liberal, seja no recrudescimento autoritário do nazifascismo e mesmo no período de relativa prosperidade material das décadas do pós-guerra, a teoria crítica voltou-se à compreensão da permanên- 
cia de relações de dominação e de exploração entre as classes sociais, estruturadas em termos capitalistas. No "Manifesto Comunista", Marx e Engels apresentam o mundo burguês como uma unidade contraditória entre fatores dinâmicos e invariabilidade estática, paradoxo de uma sociedade que só pode se reproduzir - e permanecer idêntica - ao custo de um incessante processo de revolução de suas forças produtivas (Musse, 1998). Herdeira do marxismo, a teoria crítica pode ser entendida como uma reflexão acerca dessa relação contraditória, mas necessária, entre a continuidade dos traços fundamentais da sociabilidade burguesa e as transformações socio-históricas em curso.

O objetivo deste artigo é analisar essa constelação de problemas com base na reconstrução de aspectos da teoria social de Herbert Marcuse e Theodor Adorno, especialmente em suas interpretações desses anos do pós-guerra. Em contraste com correntes no pensamento sociológico que viam o início de uma nova era das sociedades modernas, esses autores se distinguem ao interpretar, cada um a seu modo, essas transformações por meio de uma refinada leitura das contradições e antagonismos desencadeados nessa nova forma do capitalismo. Tanto as considerações de Marcuse sobre a racionalidade tecnológica quanto as interpretações de Adorno acerca do conflito social compõem uma análise atenta a essa dialética entre o velho e o novo, entre fatores dinâmicos e certa invariância estática.

Assim, após um breve reexame da polêmica ocorrida no interior do Instituto de Pesquisa Social acerca do caráter da sociedade nazista, e de uma discussão sobre como Adorno e Marcuse refletiram acerca desse momento histórico, nos concentraremos nas análises dos frankfurtianos sobre as décadas do pós-guerra, chamando atenção para a explicação particular oferecida pelos autores a respeito de temas como o desenvolvimento tecnológico e a construção do estado de bem-estar social. Como conclusão, além de recompor os principais argumentos do artigo, a proposta será refletir sobre a atualidade da teoria crítica.

Os tempos do nazifascismo: a sucursal do inferno e a pré-história

Para entender o exame simultâneo das transformações do capitalismo e da manutenção de traços essenciais da sociedade burguesa, talvez seja útil partir do momento em que as discussões sobre certas mudanças históricas ocuparam lugar central na teoria crítica. Diante da crescente intervenção estatal no andamento da acumulação de capital, o conceito de "capitalismo de estado" de Pollock seria o pressuposto econômico que balizaria o pensamento dos frankfurtianos, estendendo sua influência até mesmo nas análises da teoria crítica do período dos "trinta anos gloriosos" (Dubiel, 1978, pp. 17-133; Nobre, 1998, pp. 21-58). 
$\mathrm{Na}$ verdade, as teses de Pollock geraram um acalorado debate entre os frankfurtianos. Se a dialética entre estática e dinâmica pode ser tomada como uma chave de leitura da teoria crítica, as formulações de Pollock parecem não ser tão decisivas ${ }^{1}$.

Seguimos uma linha de interpretação das obras dos frankfurtianos que procura tomá-las como uma crítica radical da sociedade burguesa, crítica que permanece válida por causa mesmo do caráter inerentemente contraditório do capitalismo. Um dos pontos mais controversos da noção de "capitalismo de estado" diz respeito à imagem para a qual o texto do economista aponta: a possibilidade de se controlar via planejamento estatal as crises econômicas capitalistas e de se administrar as relações entre as classes. Ao alterar substancialmente as leis econômicas, o estado deslocava o lucro como motor do mercado. A dominação de classe passaria a ser exercida de forma mais imediata, o que explicaria o peso das determinações políticas sobre as econômicas.

O controle governamental da produção e da distribuição fornece os meios para eliminar as causas econômicas de depressões, processos de destruição cumulativos e desemprego de capital e trabalho. [...] Onde outrora o economista quebrou sua cabeça para resolver o enigma do processo de troca, ele se encontra, sob o capitalismo de estado, apenas com simples problemas de administração (Pollock, 1941, p. 217).

Embora compreendendo que os antagonismos de classe já não pudessem conduzir a uma transformação radical da sociedade, uma vez que as relações entre capital e trabalho passaram a ser mediadas crescentemente pelo estado, a teoria crítica nunca deixou de indicar a permanência desse conflito, nem mesmo no período em que o terror nazista havia aniquilado as organizações dos trabalhadores. Em carta a Horkheimer, Adorno tece comentários bastante ácidos acerca do trabalho de Pollock, com especial atenção para a possibilidade de se contornar as crises por meio do planejamento estatal. A principal crítica de Adorno pode ser resumida como se segue: Pollock trataria a sociedade capitalista de maneira não dialética, em que "uma economia não antagônica seria possível em uma sociedade antagônica” (Adorno, 2004, p. 139). Essa citação resume bem as intenções da teoria crítica e de Adorno, em particular. Para entender essa direção tomada pela teoria crítica, nos voltaremos para

1. A tese a respeito da inflexão da teoria crítica nos anos de 1940, e cujo eixo seriam as considerações de Pollock sobre o “capitalismo de Estado", tem sido refutada nos últimos anos, já que uma série de autores aponta para as particularidades da recepção daquelas considerações, especialmente por parte de Horkheimer e Adorno. Dessa forma, como este mesmo colocou, faltaria aos textos de Pollock algo sem o qual o capitalismo não poderia ser concebido, mesmo com a possibilidade de sua direção por meio do estado: a contradição. Ver Braunstein (2011, pp. 129-160), Puzone (2016) e Regatieri (2015). 
os ensaios "Alguns implicações sociais da tecnologia moderna" (1941), de Marcuse, e "Reflexões sobre a teoria de classes" (1942), de Adorno.

Ambos partem de uma discussão sobre o fim do capitalismo liberal e da passagem para o que seria o capitalismo monopolista. Nenhum deles ignorava que a tendência central da sociedade burguesa se dirigia a crises socioeconômicas e que parte das transformações no seio do liberalismo devia ser explicada pela tentativa de se contornar a ameaça de implosão do sistema. Por seu turno, Adorno e Marcuse buscaram compreender por que o caráter contraditório da sociedade não se fazia explodir.

Em "Reflexões sobre a teoria de classes", Adorno estabelece uma distinção entre as sociedades modernas do capitalismo liberal e o seu decurso tardio. Ambos os momentos se configurariam com base na dominação e na exploração - nos termos do autor, a "carência preparada para a dominação" (Adorno, 1978b, p. 381). Contudo, se no período liberal o conceito de pauperização expunha as contradições de uma sociedade que, no mesmo movimento, produzia riqueza e pobreza social, no capitalismo monopolista o progresso da acumulação paralisa a dinâmica da miséria. Embora não se elimine a reprodução das desigualdades de classe, o antigo elo entre a miséria e a força para a revolução se dissolvera, dando lugar a uma lógica mais complexa de reprodução do existente.

Uma forma anônima de dominação social entra em cena. Além de seus efeitos econômicos, os movimentos de centralização e concentração de capital tornaram as classes sociais invisíveis uma para a outra. Comandado pelos monopólios, o domínio de classe sobrevive de maneira objetiva. Adorno chama atenção para o caráter duplo no conceito de classe que só se tornaria manifesto após o fim do período liberal. De um lado, seria inegável o desaparecimento da antiga unidade de classe, sobretudo em sua tradução em igualdade imediata de interesses socioeconômicos e políticos. De outro, embora não possa ser ignorado pela teoria, essa dissociação não desmente em absoluto que, sob o monopólio, as classes sociais sobreviveram, pois o sentido objetivo do conceito de classe - isto é, a posição de patrões e trabalhadores no processo de produção - se manteve inalterado (Idem, p. 377).

O fascismo mostra-se como a forma de organização política própria ao capitalismo monopolista, mas a aparência de uma sociedade que administra seus conflitos e crises oculta, na verdade, a desordem de sua essência. Adorno se aproxima das teses de Franz Neumann em Behemoth, antagonista das análises de Pollock. Como o próprio título de sua obra sugere, em alusão ao trabalho de Hobbes sobre a guerra civil inglesa, muito mais do que um corpo coeso e orgânico, o nazismo seria marcado por conflitos sociais ininterruptos, especialmente no interior dos grupos dominantes: "os antagonismos do capitalismo estão operando na Alemanha em um nível maior e, por isso, mais perigoso, mesmo que esses antagonismos estejam 
encobertos por um aparato burocrático e pela ideologia da comunidade do povo" (Neumann, 2009, p. 227).

Essa imagem não passaria despercebida por Marcuse. $\mathrm{O}$ cerne de seu artigo sobre as implicações da tecnologia na sociedade da época era mostrar que a eficiência e a racionalização da produção capitalista, na Alemanha nazista, só tiveram lugar por sua aliança intrínseca com o terror. De fato, a esse caráter contraditório corresponderia algo para o qual a teoria crítica chamava atenção desde os anos de 1930, o fato de que o "reino de terror" nazista não poderia ser sustentado apenas mediante força brutal. Igualmente importante era a análise da "engenhosa manipulação de poder" que acompanha o desenvolvimento técnico do capitalismo (Marcuse, 1999, p. 74). Como corolário da centralização e da concentração de capital, a crescente expansão do aparato produtivo levou a uma racionalização geral da vida social.

Os processos de inovação tecnológica criavam novos e mais rigorosos padrões de eficiência econômica e de eliminação de desperdícios que se tornavam vitais para a acumulação de capital. Porém, essas transformações não se restringiram à organização dos parques industriais. A racionalidade de base tecnológica que se expandia para além dos processos produtivos alicerçava os fundamentos de outro tipo de dominação social e de uma nova conformação ideológica. A lógica de operação das máquinas, o mesmo esquema que servia para padronizar a intensificar a produção, é transferida para o domínio das ações humanas. Conforme a produção capitalista se expande e seu aparato técnico se desenvolve, os indivíduos tendem a agir nas diversas esferas da vida social como se fossem trabalhadores diante das máquinas, isto é, meros apêndices, dependentes do movimento imposto pela personificação do capital. A isso Marcuse chamou de "mecânica da submissão" (Marcuse, 1999, p. 82).

A aceitação da sociedade capitalista enquanto tal não significaria que suas contradições fossem imperceptíveis. Todavia, diante do risco permanente de sua aniquilação pelo terror nazista, a adaptação às relações sociais burguesas se afirma como um imperativo categórico, impelindo os indivíduos a gastar boa parte de suas energias psíquicas preocupados com a própria sobrevivência. Adorno expressa assim o significado do predomínio dessa racionalidade: "A organização total da sociedade por meio do big business e de sua técnica onipresente ocupou tão completamente o mundo e a imaginação que a ideia de que se poderia ser totalmente diverso tornou-se um esforço quase desesperado" (Adorno, 1978b, p. 376).

Para as classes dos trabalhadores, isso teria profundas repercussões, uma vez que a adaptação implicada pela racionalidade tecnológica levou à subordinação das organizações operárias. É certo que não restava muito a elas no período nazista, tamanha sua destruição. Contudo, as análises da teoria crítica não tinham como objeto apenas a Alemanha, pois também levavam em conta o desenvolvimento do 
capitalismo em outros países centrais, sobretudo os Estados Unidos. Tanto para Marcuse quanto para Adorno, sindicatos e partidos operários foram absorvidos pela lógica imperante, de tal forma que seus interesses e atitudes passam cada vez mais a depender do sucesso do desenvolvimento técnico e da racionalização da produção (Marcuse, 1999, p. 87-88; Adorno, 1978b, p. 379-381). Se os sindicatos também se tornaram grandes monopólios, a própria percepção dos trabalhadores acerca da luta de classes se alterou.

Como expressões da realidade contraditória, é preciso estar atento para os aspectos tanto dinâmicos quanto estáticos postos por essas transformações sócio-históricas. As classes permaneceriam como termo essencial à teoria crítica, uma vez que a sociedade continua a se mover pela divisão entre explorados e exploradores. Por outro lado, seria preciso modificar o conceito, pois a grande maioria dos indivíduos já não se vê enquanto tal.

Posto isso, é possível chamar a atenção para uma particularidade dos debates da teoria crítica a respeito das transformações do capitalismo e do caráter específico da sociedade nazista. Certamente, todos os seus autores reconheciam uma alteração profunda nos processos de acumulação do capital entre o final do século XIX e as primeiras décadas do século Xx. Porém, os textos de Adorno e Marcuse buscam compreender as bases de legitimação do nazifascismo como a extensão da lógica da sociedade burguesa. Eles falaram de uma nova fase do capitalismo, mas o fizeram chamando atenção o tempo todo para o fato de que a pré-história ainda não havia sido superada, para relembrar a paráfrase de Adorno que abre seu ensaio sobre a teoria de classes (Adorno, 1978b, p. 373). A crítica da economia política não havia perdido seu objeto com a possibilidade da suspensão das crises e o suposto controle do mercado, tal como argumentou Pollock. Na verdade, ela ajudaria a entender que toda a trajetória histórica da humanidade até os dias de hoje se baseou em exploração e dominação. Sua tarefa consistiria, então, em mostrar como as tendências da sociedade capitalista operavam no seio das assim chamadas sociedades avançadas. Ela implicaria o reconhecimento das dificuldades de um renovado diagnóstico de época. Afinal, se a dialética entre estática e dinâmica é intrínseca a esse modo de produção, seu desenvolvimento histórico no período do pós-guerra lançaria um conjunto de questões marcadas, ao mesmo tempo, pela novidade e pela permanência.

Os anos do pós-guerra: afluência e latência

O fim dos conflitos da Segunda Guerra Mundial representou, para parte da reflexão sociológica, o início de uma nova era. Junto aos massivos investimentos para a reconstrução da Europa, outras tendências socioeconômicas promoviam um 
ambiente de grandes expectativas com relação ao futuro das sociedades modernas. Suplantando a escassez e as crises do capitalismo liberal, uma nova configuração do poder estatal dotada de mecanismos de intervenção econômica de matiz keynesiana e de instituiçóes promotoras de direitos de bem-estar social encontrava-se com um regime particular de acumulação de capital baseado no binômio produção e consumo de massa. Esse arranjo social fordista alicerçaria os pressupostos da expansão capitalista no pós-guerra ao estabelecer um equilíbrio tenso entre as classes sociais: de um lado, o capital corporativo das grandes empresas que trocara as turbulências da etapa anterior por um caminho mais suave em busca de lucratividade segura, mas limitada; de outro, os sindicatos e seus trabalhadores organizados que, gozando de maior padrão de vida e de menor oscilação nos níveis de emprego, abandonavam antigos projetos revolucionários pela seguridade social (Harvey, 2007, p. 129).

Grosso modo, essa literatura acadêmica pode ser sintetizada pelo conceito de sociedade pós-industrial de Daniel Bell2. Segundo o autor de The coming of post industrial society, se em seu período clássico as sociedades ocidentais se articulariam por relaçôes vincadas na propriedade privada, pela condução da política por elites e por uma cultura baseada em satisfações restritas e postergadas, as profundas transformações na estrutura ocupacional e, principalmente, a crescente influência da ciência e da tecnologia que se verificavam naqueles decênios não incidiriam apenas sobre o setor manufatureiro, mas conformariam a política, as relações sociais mais gerais e as disposições subjetivas dos indivíduos. Enquanto disputas ideológicas marcariam o período anterior, essa nova sociedade afluente se assentaria em consensos sobre um estado assistencial, a descentralização e o pluralismo político e um sistema de economia mista defendidos, sobretudo, por cientistas e intelectuais que transcendessem suas limitações de classe. Embora não eliminasse as desigualdades e distinções sociais, os conflitos seriam dirimidos por considerações de ordem técnica, alicerçadas por uma racionalidade calculadora e instrumental (Bell, 1999, p. XCVII).

Conquanto se debruçassem sobre o significado dessas transformações, Adorno e Marcuse não partilhavam do mesmo entusiasmo dessas vertentes do pensamento social. Em primeiro lugar, em suas interpretações sobre o fenômeno do nazifascismo, os frankfurtianos apontavam não apenas para a realização de tendências que já estariam latentes na aurora das sociedades modernas como, também, para certos traços que, já na década de 1940, davam impressão de persistir para além daqueles tempos autoritários. No mesmo sentido, Adorno e Marcuse não se furtaram à ta-

2. Embora os frankfurtianos não discutissem especificamente a obra de Bell, ela talvez seja a formulação mais bem-acabada dessas teses que, em curto espaço de tempo, se tornaram hegemônicas no meio acadêmico da época. Para uma discussão sobre o conservadorismo social e político que vicejava nos meios universitários nos Estados Unidos em meados da década de 1960, ver Cotkin (1997). 
refa de interpretar as contradições e os antagonismos que se reproduziam por esse arranjo marcado pela ascensão das democracias de massas e pela consolidação de um estado de bem-estar social. Ainda que ressaltassem desdobramentos específicos e os interpretassem de maneira algo distinta, a preponderância de relações de produção capitalistas sobre o desenvolvimento das forças produtivas é elemento-chave seja no conceito marcuseano de sociedade industrial avançada, seja na noção adorniana de mundo administrado.

Em O homem unidimensional, a utilização em larga escala da ciência e da tecnologia na produção e na circulação de mercadorias permanecia um fenômeno social decisivo para Marcuse. Ao multiplicar a capacidade produtiva de bens materiais e de excedentes, apaziguar o interior das fábricas por transformar o trabalho em algo menos estafante e descolar a identidade imediata da exploração econômica da figura do capitalista, esses processos não se circunscreveriam a questôes concernentes ao provimento de produtos industrializados para o conjunto da população. Satisfazendo, à primeira vista, demandas de diferentes grupos da sociedade, a amplificação tecnológica da ratio alteraria os próprios termos da alienação capitalista. Se, na época de Marx, o trabalho realizado pelo proletariado era indissociável da extenuação física e de sua miséria econômica, nessas sociedades industriais avançadas haveria um conjunto maior de mercadorias disponíveis para compor os salários de segmentos importantes dos trabalhadores e a velha fadiga muscular seria substituída pela tensão psicológica, pela padronização das atividades e por uma enervante rotina.

Contudo, ainda que permitisse um padrão de vida inimaginável para qualquer formação social do passado, esse avaro véu tecnológico subministraria paliativos a fim de conter processos verdadeiramente revolucionários no seio das sociedades modernas. O progresso que se impõe sobre os indivíduos orienta-se consoante a exploração do trabalho humano e a apropriação de mais-valia. Ele já não mais se efetiva avançando extensivamente sobre as áreas pré-capitalistas, mas sobretudo pela intensificação das modernas relações econômicas e da malversação dos resultados obtidos pela ciência para fins não-humanos. Esta, comprometida desde o seu interior, forja o momento histórico no qual a automatização e a eficiência industrial, que poderiam chegar até o limite técnico de tornar o trabalho algo residual, são utilizadas para difundir restrições e manipular carências.

Por meio dessa malfazeja relação entre as novas forças produtivas e as velhas relações de produção, a sociedade aprisiona-se ao trabalho e paralisa a vida social. Tais processos, porém, não desencadeariam um movimento de rebeldia contra as normas e as relações de propriedade vigentes, ao menos entre os grupos mais tradicionais de contestação social, ao contrário, ela contribuiria vivamente para a perpetuação do capitalismo. Todavia, apesar de se mostrar capaz de impedir a revolução socialista 
em um futuro próximo, esse novo arranjo traria consigo tendências destrutivas cada vez mais vigorosas. A ideia iluminista de progresso é corrompida e os objetivos pelos quais ela deveria se pautar - isto é, aqueles definidos pelas possibilidades de uma real melhora da condição humana - são substituídos pelo enganoso e artificial prolongamento do reino da necessidade.

Sua produtividade destrói o livre desenvolvimento das necessidades e faculdades humanas, sua paz, mantida pela constante ameaça de guerra, seu crescimento, dependente da repressão das reais possibilidades de pacificação da luta pela existência - individual, nacional e internacional. [...]. Nossa sociedade se distingue pela conquista das forças sociais dissidentes mais precisamente pela Tecnologia do que pelo Terror, sobre a dupla base de uma eficiência esmagadora e de um crescente padrão de vida (Marcuse, 2015, pp. 31-32).

Em contraste com a inumerável quantidade de mercadorias que ela fornece, germinariam alternativas escassas no interior dessa sociedade afluente. De acordo com Marcuse, o imperativo de desperdiçar suas capacidades técnicas e econômicas a fim de preservar os fundamentos da opressão social encontra um número reduzido de saídas. O seu sucesso dependeria de uma combinação entre as características do Estado de Bem-Estar Social - Welfare State - e do Estado de Guerra - Warfare State.

A crescente produtividade do trabalho, o aumento dos índices de natalidade sobretudo nas camadas inferiores da população -, a permanente economia de defesa, a integração político-econômica dos países capitalistas centrais e a intensificação de suas relações com áreas economicamente subdesenvolvidas fortaleceriam tendências que mantêm a união entre as classes em parâmetros desconhecidos e compõem um círculo vicioso por meio do qual o fortalecimento do poderio militar das naçóes e a crescente capacidade produtiva da indústria se requerem continuamente. Não se trata de vencer uma batalha específica ou superar os impasses gerados pela carência material, mas de estimular uma engrenagem que se impõe pelas necessidades que ela mesma produz e de abrandar as malfadadas consequências acarretadas pela irracionalidade de sua perpetuação sistêmica.

Essa engrenagem societária se cristalizaria em uma espécie de fechamento do universo político. Porém, ao dispensar um tratamento brutal que reviveria práticas medievais e do início da era moderna àqueles que, mesmo nos países centrais do capitalismo, encontravam-se às margens de sua afluência, essa sociedade industrial avançada agudiza contradições que não a deixam ser encarada como um todo unidimensional. Ainda que grande parte da classe trabalhadora tenha se tornado uma classe da sociedade burguesa (Marcuse, 1972, p. 5), o frankfurtiano destaca também o potencial de irrupção e de efervescência social constituído pelos trabalhadores não 
abarcados nas estruturas do bem-estar social, pelas mulheres, pelos negros e pelas lutas contra o colonialismo. Vítimas da lei e da ordem, esses marginalizados pelo sistema revelariam que a aparente estabilidade daqueles anos dourados do capitalismo era garantida não apenas pela satisfação de falsas necessidades, mas também pela contenção violenta de quem não se enquadra nas regras de um jogo viciado. É a política que se mantém presa à economia, e não o seu contrário.

A realidade do pluralismo se torna ideológica, ilusória. Parece ampliar, em vez de reduzir, a manipulação e a coordenação; promover, em vez de contrariar, a integração decisiva. As instituições livres competem com as autoritárias em transformar o Inimigo em força mortífera dentro do sistema. Essa força mortífera estimula o crescimento e a iniciativa não em virtude do vulto e do impacto econômico do "setor" da defesa, mas em virtude do fato de a sociedade como um todo se tornar uma sociedade de defesa. [...]. Nem a produtividade crescente e nem o alto padrão de vida dependem da ameaça externa, mas os seus usos para a contenção da transformação social e para a perpetuação da servidão dependem sim. O Inimigo é o denominador comum do que é feito e desfeito. E o Inimigo não é o mesmo que o comunismo ou capitalismo atual - é, em ambos os casos, o espectro real da libertação (Marcuse, 2015, p. 65).

Tal como em Marcuse, as décadas do pós-guerra levaram Adorno à construção de um novo diagnóstico de época, agora sintetizado na noção de mundo administrado ${ }^{3}$. Efeito de um tempo no qual não apenas as práticas e as formas de trabalho, mas a própria organização do lazer e do tempo livre é submetida aos imperativos do processo de valorização do capital, a reificação se expande pela totalidade do tecido social e prolonga a não-liberdade de relações industriais para o âmago da vida cotidiana. Ainda que a força dos sindicatos e a construção de um estado social tenham sido bem-sucedidos em restringir a duração legal da jornada diária de trabalho, trata-se de um momento no qual os indivíduos são impelidos a se identificar com seus papéis sociais, confirmando de modo farsesco a teoria da alienação de Marx (Musse, 2016, p. 121).

3. Malgrado as análises sobre certo déficit sociológico em seu pensamento tardio (Honneth, 1993), o exílio estadunidense e, principalmente, o seu retorno à Alemanha na década de 1950 foram os momentos nos quais Adorno elaborou suas mais instigantes contribuições à sociologia (cf. Jay, 1988, p. 32), seja pela elaboração de pesquisas empíricas - destaca-se, por exemplo, As estrelas descem à Terra, escrito em 1953 -, seja em ensaios críticos sobre clássicos da disciplina e sobre vertentes coetâneas do pensamento social, que culminariam na célebre controvérsia sobre o positivismo alemão ao longo dos anos de 1960 para uma análise dessas críticas de Adorno à sociologia, ver Vasconcellos (2012; 2014). A esse respeito, Wiggershaus é enfático ao afirmar que além de suas aulas na Universidade, da retomada de "suas antigas atividades de crítica musical e crítica de arte, e da adoção de novas atividades de crítica da civilização e de teórico da literatura, Adorno tornou-se sociólogo" (Wiggershaus, 2002, p. 487). 
Longe de uma forma superior de organização social, a dominação sobre os seres humanos ainda continua a ser exercida mediante o processo econômico. No plano de sua aparência, a engrenagem parece deslizar sem fissuras. $\mathrm{O}$ ideal utópico se restringe ao interesse pela manutenção do status quo e pela plena ocupação das forças produtivas, enquanto a reivindicação de libertar-se do trabalho heterônomo não é sequer ouvida. Embora já seja possível organizar o mundo para que a possibilidade de viver sem passar necessidade se realize plenamente, a fria exigência econômica, sintetizada pelos interesses do lucro e da dominação, permanecem prendendo as sociedades em suas antigas relaçôes de produção, ainda fundamentalmente capitalistas. A dialética social que entrelaça progresso à regressão, momentos dinâmicos à estática de formas de propriedade que perderam qualquer justificativa racional, permanece inalterada, embora esses seus processos não se realizem de maneira pacífica e sem contradições.

O poderio das relações de produção, que não foram revolucionadas, é maior do que nunca, mas, ao mesmo tempo e em todos os lugares elas estão, enquanto algo objetivamente anacrônico, enfermas, prejudicadas, esvaziadas. Elas não funcionam mais por conta própria. Ao contrário do que pensa a antiga doutrina liberal, o intervencionismo econômico não é enxertado de um modo estranho ao sistema, mas de modo imanente a ele, como a quintessência da autodefesa do sistema capitalista: nada poderia explicar de modo mais contundente o conceito de dialética. De maneira análoga, na Filosofia do direito de Hegel [...] o Estado, que intervém a partir de fora, supostamente alheio ao jogo das forças sociais, e atenua os antagonismos com ajuda policial, é invocado com base na dialética imanente da própria sociedade, que, para Hegel, de outro modo desintegraria (Adorno, 1986, pp. 72-73).

É oportuno retomar as análises de Adorno sobre os conflitos sociais nesses tempos pretensamente novos do pós-guerra. Em "Considerações sobre o conflito social hoje”, Adorno se contrapõe ao modo pelo qual certas vertentes da sociologia estadunidense e alemã - nominalmente, Lewis Coser e Ralf Dahrendorf - traduziriam a doutrina marxista da luta de classes em estilo positivista. De acordo com o frankfurtiano, essa abordagem do social conflict hispostasia o caráter antagônico da sociedade, substancializando o conflito como forma de socialização primária e universal. Se essas correntes acertam ao perceber o momento histórico no qual as relações entre as classes sociais parecem ter sido incorporadas na estrutura funcional da sociedade, elas se equivocam ao não perscrutar a mediação entre essa miríade de conflitos pseudoprivados e a objetividade social. Pois, tal como no riso, em que o como e o do que se ri acompanham a dinâmica histórica da sociedade, os momentos nos quais pessoas incorrem em hostilidades recíprocas só são compreendidos quando 
se percebe neles a expressão de momentos sociais que estão além da motivação direta dos mesmos e que, por vezes, ocultam essas motivações.

A expectativa de que os conflitos e os antagonismos sociais possam ser analisados pelo prisma de sua capacidade de promover coesão social esbarra no fato de que as regras do jogo de arbitragem que mantêm os conflitos dentro de limites aceitáveis isto é, quando seus disputantes abdicam da aniquilação do outro - são sedimentos de processos sociais que não foram acordados livremente. Ao ser encarado dentro desses parâmetros, o potencial transformador que poderia estar contido em cada conflito é ignorado. A adequação prévia da rebeldia e das reivindicações políticas às normas vigentes é a condição fundamental para que essa abordagem sociológica acrítica volte suas atenções para a análise de qualquer irrupção social. Em suma, o conflito social é coisificado por meio da adequação dos indivíduos e das classes sociais a papéis e instituições tentando tornar invisível a violência por detrás da reprodução da sociedade.

Restaura-se sem o menor reparo a tese de Spencer segundo a qual a integração progressiva se encontraria em interdependência com uma diferenciação progressiva. Entretanto a quantidade da integração foi trocada na qualidade contraposta: inibiu-se a diferenciação enfática que não se demonstrava até que os indivíduos se desenvolvem livremente. A multiplicidade aparente das lutas estimuladas oficialmente, cobertas por assim dizer por uma espécie de abóboda, dos conflitos sociais que estão previstos pelo esquema afinado, parodia uma situação sempre desunida em favor da manutenção das relações existentes (Adorno, 1978a, p. 181).

Adorno funda suas interpretações em uma complexa reflexão sobre a essência e a aparência dessas sociedades. Por trás desse processo global, que arrasta consigo tudo o que é qualitativamente diferenciado, agitam-se mecanismos e processos de produção material e de coerção social que se mantêm subordinados a uma regularidade cega e irracional. Apesar de toda intervenção econômica e do planejamento da produção global de mercadorias, que diluíram as fronteiras entre a produção material, distribuição e consumo, a antiga desigualdade ainda vigora.

A expansão da técnica produz uma falsa identidade entre indivíduo e sociedade. Segundo Adorno, o princípio de identidade, originado na comparabilidade abstrata do trabalho social, arruína toda particularidade até o seu aniquilamento. Uma vez que não renuncia à distinção entre essência e fenômeno, o prisma adorniano não aceita esta desordem - a atual sociedade antagônica -, mas a critica em sua contradição com aquilo que se manifesta historicamente. $\mathrm{O}$ caráter abstrato do valor de troca está vinculado a priori à denominação do universal sobre o particular, da sociedade sobre seus membros. Porém, como a essência oculta constitui a desordem, 
a desigualdade dos supostos equivalentes que são intercambiáveis, a racionalidade objetiva da sociedade em sua dinâmica se afasta cada vez mais do modelo da razão lógica. Tal afastamento é fruto da manifestação da essência da sociedade que, em vez de dotá-la de sentido, traz à tona sua inverdade.

Assim, aquilo que permanece incompreensível para os indivíduos - a sociedade e os processos sociais que se realizam às suas costas - ressurge em meio a conflitos sociais periféricos. Face inversa de uma falsa integração, o potencial de desintegração irrompe o contexto geral de ofuscamento por meio de uma agressão voraz e mal dirigida. Quem ainda não é imanente ao sistema, seja como força de trabalho, seja como consumidor, sofre com o movimento irracional do todo. Com a racionalização técnica da produção, já não há mais nenhum adversário palpável e as disputas se dão contra personificações dos interesses do capital, contra fantasmas que enfrentam em si mesmos a "pressão de ter que cuidar do rendimento devido da produção" (Adorno, 1978a, p. 179).

A contradição decisiva não é reconhecida como conflito de classes. $O$ desenlace histórico converteu as sociedades modernas em uma totalidade antagônica, na qual cada um dos seus conflitos particulares assume a forma de uma imagem encobridora dessa sociedade. A violência da perpetuação dos processos que produzem as classes se dispersa por outras vias. Em nível macrológico, o nacionalismo - fundado por meio de uma solidariedade dirigida e comercializada que compóe a base de uma comunidade do povo criada, por exemplo, pelos vínculos artificiais existentes entre os fanáticos por futebol - canaliza a essência destrutiva da sociedade por meio dos conflitos políticos imperialistas. Em nível micrológico, desvia-se essa mesma energia da luta de classes alienada de seu fim primeiro para o refúgio do âmbito privado, que se asperge por meio de conflitos cegos e autoinfligidos, nos quais a sociedade cobra a conta por sua falsa configuração. Petrificado e emudecido, o movimento da sociedade conforma-se em reproduzir suas bases materiais - a invisibilidade das classes se imiscui na petrificação de sua relação.

Assim, os estigmas e os estereótipos condensam relações e tensões sociais. Percorrendo toda sorte de matizes, do riso malicioso à violência física, o ódio se volta contra algo que se tem que reprimir dentro de si. Os indivíduos compartilham um idêntico destino - a brutalidade socialmente ritualizada condena o particular como perturbador do universal. Quem ousa se rebelar contra as proibições codificadas e as instituições competentes ou mesmo se limita a questionar o sentido destas, desafia os demais a lhe impor travas. Difundida em toda sociedade, a lógica da situação pretende dominar de forma incontrovertida não só por meio daqueles que se prestam ao papel de guardião da ordem, mas por intermédio dos homens que se identificam de forma exagerada com ela. Os que ainda não estão adaptados enfrentam o rigor de 
erupções irracionais. Espera-se que se coisifique definitivamente a espontaneidade, pois essa constitui uma ameaça à forçada e instável harmonia social.

\begin{abstract}
No entanto, nem tão raramente originam-se conflitos, exatamente nas máquinas e nos aparatos da esfera do consumo, assim que algo, para falar com a nova língua alemã, "não transcorra corretamente". [...] A briga de família tem início, pois o aparelho de televisão não funciona, em frente ao qual o grupo primário reunido gostaria de, novamente, acompanhar a luta de boxe já há muito decidida. Àqueles que foram logrados em sua diversão sintética, o círculo familiar oferece a oportunidade bem-vinda de colocar para fora o que nada tem a ver com as pessoas ali presentes. Estes tornam-se objetos para os outros - das relações de troca entre os vendedores e os consumidores, superficialmente inocentes, passando por mecanismos mais ou menos ocultos de dominação e administração, por clínicas e casernas, até as prisões e os campos de concentração (Adorno, 1978a, p. 191).
\end{abstract}

\title{
Considerações finais: sobre a atualidade da teoria crítica
}

Segundo importante matriz de comentadores, os anos do pós-guerra desvelariam limites internos ao prisma dos frankfurtianos. Se, na fase do materialismo interdisciplinar, a teoria crítica se notabilizou por associar uma adensada reflexão teórica à condução de pesquisas empíricas, o paradigma da crítica à razão instrumental enveredava por aporias conceituais que bloqueavam as possibilidades de composição de uma teoria social. Malgrado as intenções dos autores, o pensamento dos frankfurtianos se descolava do movimento do todo ao descrever as sociedades modernas em seu decurso tardio como um arranjo administrado, uma ordem unidimensional sem espaço para qualquer contradição estrutural e, por fim, sem nenhuma possibilidade objetiva de emancipação social (Benhabib, 1996; Habermas, 2012; Honneth, 1993).

Todavia, a leitura dos ensaios de Adorno e de Marcuse permite fundamentar uma interpretação distinta. Tanto nas análises sobre os tempos do fascismo como nas reflexões sobre os anos do pós-guerra, Adorno e Marcuse se contrapuseram a interpretações que pressupunham essa imagem idealizada das sociedades, desvelando as contradições objetivas desencadeadas pela dialética entre fatores dinâmicos e certa invariância estática, entre transformações nos processos e nos instrumentos de produção e a reiteração de velhos princípios ligados à exploração econômica e à dominação social. Assim, enquanto Adorno chamava atenção para os efeitos da permanência de uma mesma estrutura objetiva de classes para a compreensão de uma miríade de conflitos e antagonismos que se aspergia por todo tecido social, Marcuse centrou seus esforços sobre os vieses da perpetuação de formas de sociabilidade burguesas na orientação e no significado do desenvolvimento científico e tecnológico. Ainda que 
seus interesses se voltassem para as análises de mecanismos de estabilização e das bases do conformismo social, os frankfurtianos também não deixaram de apontar para algumas fissuras e cisões que poderiam promover um ambiente de questionamento e de rebeldia contra os princípios estruturantes das sociedades capitalistas em suas mais diversas configurações históricas.

Ademais, nossas discussões sobre o pensamento de Adorno e de Marcuse não se restringem a uma exegese dos textos dos frankfurtianos. Uma teoria crítica que pretenda continuar as tarefas de seus autores originais não pode simplesmente se prender ao conteúdo de seus textos, ainda que o diagnóstico de seu presente histórico permaneça atual. Como insistimos ao longo deste artigo, a sociedade capitalista permanece a mesma em sua essência, um conjunto de relações sociais que escapa do controle dos indivíduos e que determina, de forma decisiva, a maneira como suas vidas se reproduzem. Dominação e exploração ainda subsistem como os elementos-chave da sociabilidade burguesa. Contudo, se essas relações são marcadamente contraditórias - não porque a análise dialética da sociedade goste de apontar esse traço como uma espécie de obsessão, mas, sim, por conta da própria configuração objetiva de seus elementos constituintes, a começar pela forma mercadoria, antítese entre valor e valor de uso -, então elas mesmas se movimentarão dentro dessas contradições.

Ao contrário das correntes que se dizem herdeiras da assim chamada antiga teoria crítica, as transformações da sociedade burguesa em suas diversas feições não implicam o abandono do diagnóstico original, preso em supostas aporias, tampouco uma reconstrução que jogue fora seus conceitos centrais. Apesar de todas as aparências, é preciso investigar de maneira reflexiva se os conceitos da teoria crítica continuam a ser pertinentes no mundo atual. Acreditamos que sim, embora isso também resulte na investigação de fenômenos e acontecimentos cujo prognóstico escapou à teoria. Para além disso, ela pode servir de inspiração para que continuemos a tarefa de uma crítica radical das relações sociais capitalistas, mesmo que este já não seja o mesmo em relação à primeira metade do século $\mathrm{XX}$.

Tal abordagem permitiria entrever aspectos cruciais das atuais formas pelas quais a sociabilidade capitalista se apresenta nos dias de hoje e que atravessam a vida de todos os indivíduos, de maneira homóloga ao exame da tecnologia e da indústria cultural. Fenômenos como a "uberização" das relações de trabalho e a onipresença das redes sociais poderiam, então, ser desvelados em sua articulação íntima com o andamento da acumulação capitalista. Exemplo paradigmático daquilo que é chamado de "economia compartilhada", aplicativos como o Uber são marcados por uma contradição: por um lado, a promessa de liberdade, tanto para o condutor, que pode dispor de seu tempo com a família, quanto para o usuário, que paga preços baratos por um serviço particular de transporte e se livra dos inconvenientes do transporte 
público ruim; por outro, a necessidade de se trabalhar horas a fio e sem descanso e a perspectiva de tornar o tempo de trabalho o mais produtivo possível ${ }^{4}$.

Por sua vez, plataformas como o Facebook anunciam a possiblidade de uma discussão livre sobre qualquer assunto, oferecendo um serviço pago por uma nova mercadoria digital - o histórico de navegação de seus usuários. Estruturado nas bolhas e nos filtros que medeiam o fluxo dos dados digitais, o próprio meio se articula como mecanismo de estímulo a traços de personalidade narcisistas e demonstra intensa afinidade eletiva como uma nova dinâmica social do preconceito, que se manifesta pelas práticas de cyberbullying, revenge porn, pelos haters, pelos discursos de ódio, pelas manifestações políticas extremistas, pela propagação de paranoias coletivas etc., que caracterizam a conduta de uma miríade de internautas. Em ambos os exemplos, o conflito social e a dependência dos indivíduos não aparecem como tais, mas eles nunca deixam de estar presentes.

Evidentemente, trata-se de simples indicações para investigações futuras, que escapam aos limites deste artigo. Além disso, elas só podem ser concretizadas por meio de um esforço intelectual coletivo, justamente aquele que marcou o nascimento e o desenvolvimento da teoria crítica, dada a complexidade dos processos que acompanham e resultam do atual estágio do capitalismo. A possibilidade dessa retomada também aponta para a pertinência e perenidade dos diagnósticos da teoria crítica.

\section{Referências Bibliográficas}

Adorno, Theodor W. (1978a), “Anmerkungen zum sozialen Konflikt heute”. In: Adorno,

Theodor W. Gesammelte Schriften, vol. 8, Soziologische Schriften I. Frankfurt am Main, Suhrkamp, pp. 177-195.

Adorno, Theodor W. (1978b), “Reflexionen zur Klassentheorie”. In: Adorno, Theodor W.Gesammelte Schriften, vol. 8, Soziologische Schriften I. Frankfurt am Main, Suhrkamp, pp. 373-391.

Adorno, Theodor W. (1986), “Capitalismo tardio ou sociedade industrial?”. In: CoHn, Gabriel (org.). Theodor W. Adorno. São Paulo, Ática.

Adorno, Theodor W. (2004), Brief und Briefwechsel, Band 4, Theodor Adorno, Max Horkheimer. Briefwechsel (1927-1969). Band II: 1938-1944. Frankfurt am Main, Suhrkamp. BELL, Daniel. (1999), The coming of post-industrial society. Nova York, Basic Books

4. Sem mencionar o fato de que esse tipo de aplicativo funciona atrelado a processos quase instantâneos de financeirização e aceleração do crédito, aliados à mais completa precarização das relações de trabalho, que não são reconhecidas como tais - condutores não são apresentados como trabalhadores a serviço de uma empresa, mas como parceiros de uma plataforma digital. 
Benhabib, Seyla. (1996), “A crítica da razão instrumental”. In: Zizek, Slavoj (org.). Um mapa da ideologia. Rio de Janeiro, Contraponto, pp. 71-96.

Braunstein, Dirk. (2011), Adornos Kritik der politischen Ökonomie. Bielefeld, Transcript.

Cот KIn, George. (1997), “The tragic predicament: post-war American intellectuals, acceptance and mass culture". In: Jennings, Jeremy \& KeMp-WelCH, Tony. (orgs.). Intellectuals in politics. London, Routledge.

Dubiel, Helmuth. (1978), Wissenschaftsorganisation und politische Erfahrung. Sutdien zur frühen Kritischen Theorie. Frankfurt am Main, Suhrkamp.

Habermas, Jürgen. (2012), Teoria do agir comunicativo. Racionalidade da ação e racionalização social. São Paulo, Martins Fontes.

Harvey, David. (2007), Condição pós-moderna. São Paulo, Edições Loyola.

Honneth, Axel. (1993), The critique of power. Massachusetts, The Mit Press.

Jay, Martin. (1988), As idéias de Adorno. São Paulo, Cultrix.

Marcuse, Herbert. (1972), Counterrevolution and Revolt. Boston, Beacon Press.

Marcuse, Herbert. (1999), “Algumas implicações sociais da tecnologia moderna”. In: MARCuse, Herbert. Tecnologia, Guerra e Fascismo. São Paulo, Editora da Unesp, pp. 72-104.

Marcuse, Herbert. (2015), O homem unidimensional. São Paulo, Edipro.

Musse, Ricardo. (1998), “A atualidade do Manifesto Comunista”. Praga, 5: 89-94.

Musse, Ricardo. (2016), "A administração do tempo livre”. Lua Nova, 99: 107-134.

Neumann, Franz. (2009), Behemoth. The structure and practice of national socialism. 19331944. Chicago, Ivan R. Dee.

Nobre, Marcos. (1998), A dialética negativa de Theodor W. Adorno: ontologia do Estado falso. São Paulo, Iluminuras.

Pollock, Friedrich. (1941), "State capitalism: its possibilities and limitations". Studies in Philosophy and Social Science, 9: 200-225.

Puzone, Vladimir Ferrari. (2016), Capitalismo perene: reflexóes sobre a estabilização do capitalismo a partir de Lukács e da Teoria Crítica. São Paulo, Alameda.

Regatieri, Ricardo Pagliuso. (2015), Capitalismo sem peias: a crítica da dominação nos debates no Instituto de Pesquisa Social no início da década de 1940 e na elaboração da Dialética do Esclarecimento. São Paulo, tese de doutorado, Faculdade de Filosofia, Letras e Ciências Humanas da Universidade de São Paulo.

Vasconcellos, Caio. (2012), "O Moloch do presente": Adorno e a crítica à sociologia. São Paulo, Alameda.

Vasconcellos, Caio. (2014), A teoria critica e Max Weber. São Paulo, tese de doutorado, Faculdade de Filosofia, Letras e Ciências Humanas da Universidade de São Paulo.

Wiggershaus, Rolf. (2002), A escola de Frankfurt. São Paulo, Difel. 


\section{Resumo}

Estática e dinâmica do capitalismo tardio na teoria crítica

O objetivo deste artigo é uma interpretação da teoria social de Theodor Adorno e Herbert Marcuse. Para tanto, reconstruímos aspectos de seus diagnósticos de época em dois momentos históricos, o nazismo e o pós-guerra europeu. Apesar de suas particularidades, Adorno e Marcuse partilham a pretensão de compreender a dialética entre aspectos dinâmicos e certa invariância estática, que caracteriza as sociedades burguesas. O desenvolvimento da teoria crítica deve ser entendido, então, como o exame dos traços permanentes da sociabilidade capitalista ao mesmo tempo que esta se transforma no curso da história. Como conclusão, apresentamos uma breve reflexão sobre a atualidade da teoria crítica para interpretar fenômenos sociais contemporâneos. Palavras-chave: Teoria crítica; Herbert Marcuse; Theodor Adorno; Capitalismo tardio.

\section{Abstract}

Static and dynamic of late capitalism in critical theory

This article construes the social theory of Theodor Adorno and Herbert Marcuse. For this purpose, we reconstruct some elements of their historical analysis in two moments, the Nazi period and the Post-War period. Although their works have peculiarities, Adorno and Marcuse shared the same intention: to understand the dialectics between dynamical traits and invariable statics which characterizes bourgeois societies in different periods. We can follow the development of critical theory as the exam of the continuous characteristics of capitalist sociability at the same time as this transforms itself in the course of history. To conclude, we present a brief reflection on the actuality of critical theory to analyze contemporary social phenomena.

Keywords: Critical theory; Herbert Marcuse; Theodor Adorno; Late capitalism.

Tem recebido em 4/4/2018 e aprovado em 13/5/2018.

DOI: $10.11606 / 0103-2070 . t s .2018 .145019$.

Caio vasconcellos é pesquisador de pós-doutorado do Departamento de Sociologia da Unicamp e bolsista Fapesp (processo 2016/11491-3).E-mail: caiovascon@hotmail.com.

VLAdimir PUzone é pós-doutorando do Departamento de Sociologia da Universidade de Brasília e bolsista PNPD/Capes. E-mail: vfpuzone@gmail.com. 